Boletín de la Sociedad Geológica Mexicana

VOLUMEN 67, NÚM. 3, 2015, P. 387-400

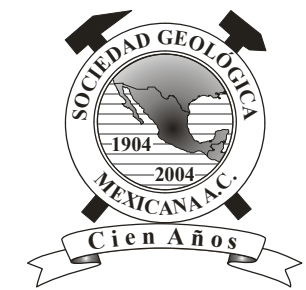

\title{
Tapetes microbianos recientes en el Manantial hidrotermal de Baño San Ignacio, Linares, Nuevo León
}

\author{
Elizabeth Chacon-Baca ${ }^{1, *}$, Leticia Alba-Aldave ${ }^{2}$, Sonia Angeles ${ }^{2}$, César Cantú-Ayala ${ }^{3}$ \\ ${ }^{1}$ Facultad de Ciencias de la Tierra, Universidad Autónoma de Nuevo León, (UANL), Carretera Cerro Prieto Km 8, Linares, Nuevo \\ León, México 67700, México. \\ ${ }^{2}$ Instituto de Geología, Universidad Nacional Autónoma de México, Circuito Exterior, Cd. Universitaria, 04510, México, D.F. \\ México. \\ ${ }^{3}$ Facultad de Ciencias Forestales, Universidad Autónoma de Nuevo León, (UANL), Carretera Nacional 85, Km 145, Linares, N.L. \\ 67700, México.
}

*baicalia2012@gmail.mx

\section{Resumen}

El manantial de Baño de San Ignacio, localizado en Linares, Nuevo León, en el noreste de México, representa un área natural protegida que alberga no solamente flora y fauna endémica, sino una abundante vida microbiana. Este sistema hidrotermal está ligado a la evolución geotectónica de aguas continentales subterráneas atrapadas en un sistema cerrado estándar. Las comunidades microbianas en el Baño de San Ignacio (de aquí en adelante referido como BSI) pueden encontrarse como tapetes gelatinosos esferoidales o bien, como tapetes bentónicos estratiformes asociados a terrazas de travertino a lo largo del canal principal. Los tapetes microbianos en el BSI exhiben una textura con apariencia de hongo y una laminación macroscópica bien definida. La diagnosis textural de los tapetes microbianos del BSI, caracterizada mediante microscopía óptica y micrografía electrónica, muestra que la matriz extracelular está organizada como una red tridimensional con abundantes fibras orgánicas donde diversas partículas sedimentarias pueden quedar atrapadas o unidas. Por otra parte, la precipitación de calcita se observó sólo en áreas muy puntuales de la matriz y a lo largo de algunos filamentos similares a Phormidium sp. La infraestructura del tapete muestra un arreglo de capas alternadas de cianobacterias, diatomeas y cristales de calcita de diferentes tamaños. Aunque cada capa tiene un grosor variable, los primeros tres centímetros verticales del tapete corresponden a cianobacterias filamentosas Oscillatoriales, mientras que entre las bacilariofitas se encuentran diatomeas pennadas principalmente de los géneros Amphora y Nitzschia. Al igual que en muchos otros manantiales hidrotermales, los microorganismos eucariontes son escasos en número respecto a los procariontes y existe una amplia gama de bacterias sin determinar. A nivel de microestructura, las diatomeas pueden estar jugando un papel mucho más significativo en la estabilización y estructura del tapete que el que tradicionalmente se reconoce. Existen zonas mineralizadas en el interior del tapete debido a que diversos sedimentos influenciados biológicamente se adhieren a las fibras poliméricas de la matriz (algunas de ellas secretadas por diatomeas); otras fibras poliméricas inclusive forman puentes orgánicos favoreciendo las interacciones microbio-mineral. La descripción de microtexturas provenientes de ambientes continentales neutros como el BSI tiene un gran potencial astrobiológico para la identificación y detección de biosignaturas microbianas sedimentarias.

Palabras clave: Baño San Ignacio, biosedimentos, tapetes microbianos, cianobacterias, diatomeas.

\begin{abstract}
The Baño San Ignacio spring, located in Linares, Nuevo Leon, northeastern Mexico, represents a natural protected area that harbors not only endemic flora and fauna, but also a rich microbial life. This hydrothermal system is linked to the geotectonic evolution of underground continental waters trapped into a closed standard circuit. Microbial communities at Baño San Ignacio (hereafter BSI),
\end{abstract}


may be found either as gelatinous spheroidal mats, or as benthic stratiform mats associated with travertine terraces along the main channel. Microbial mats exhibit a marked fungal-like appearance and a well-defined macroscopic lamination. The textural diagnosis in BSI mats, characterized by optical microscopy and electronic scanning, shows that the extracellular matrix is organized as a three-dimensional network with abundant organic fibers where sediments may be trapped or bound. On the other hand, carbonate precipitation was observed only in small localized areas of the matrix and along some Phormidium-like filaments. The internal mat structure is organized as alternating layers of cyanobacteria, diatoms and variable-sized calcite. Although mat thickness is variable, the first centimeters of each mat correspond to Oscillatoriales belonging to the filamentous cyanobacteria, while pennate diatoms correspond to Amphora sp. and Nitzschia sp. As in many other hydrothermal springs mats, eukaryotic microorganisms are relatively scarce and many other bacteria have yet to be identified. At the microstructural level, diatoms may be playing a more significant role in mat structure and stability than traditionally acknowledged. The internal mat structure shows mineralized patches because diverse biologically-influenced sediments attach to polymeric fibers (some of them secreted by diatoms) from the EPS matrix; other polymeric fibers may even form organic bridges favoring microbial-mineral interactions. The description of microtextures from neutral environments in continental settings such as BSI holds a great astrobiological potential for the identification and detection of microbial signatures.

Keywords: Baño San Ignacio, biosediments, microbial mats, travertine, cyanobacteria, diatoms.

\section{Introducción}

Los tapetes microbianos están formados por diversas comunidades bentónicas organizadas en capas de acuerdo a sus capacidades metabólicas (Stal y Caumette, 1994; Stolz, 2000). Además del gradiente geoquímico establecido como resultado de la diversidad microbiana de estas complejas comunidades, existen fluctuaciones en las concentraciones de solutos, gases y metabolitos (van Gemerden, 1993), aunadas a las variaciones diurnas derivadas de las tasas fotosintéticas, de respiración y/o reducción (Cohen y Rosenberg, 1989). Por su gran versatilidad metabólica y su capacidad para proliferar en diversos ambientes sedimentarios, los tapetes microbianos han persistido temporal y espacialmente a través de la historia geológica. De hecho, muchos tapetes microbianos están asociados a la precipitación de carbonatos, por lo que han jugado un papel fundamental en el ciclo biogeoquímico del carbono (Schidlowski y Aharon, 1992; Des Marais, 2003). Incluso se ha propuesto que la formación de tapetes microbianos en ambientes carbonatados representó una reserva importante dentro del ciclo global del carbono y un aumento en la productividad biológica desde el Precámbrico (Hoehler et al., 2001). Los tapetes microbianos más antiguos se han preservado tanto en forma de estromatolitos como de depósitos extensos en rocas siliciclásticas (Noffke et al., 2006), si bien los estromatolitos constituyen la evidencia paleontológica más antigua de vida en el planeta, con una edad aproximada de $3460 \mathrm{Ma}$ (Lowe, 1980; Allwood et al., 2006). Otras localidades precámbricas casi tan antiguas como los estromatolitos también muestran evidencias de tapetes microbianos fosilizados (Westall et al., 2006; Noffke y Paterson, 2008), por lo que probablemente durante el Arqueano las interacciones microbio-mineral se manifestaban en forma de consorcios microbianos de diversas morfologías y en una gran diversidad de ambientes sedimentarios.

Desde las primeras descripciones sobre tapetes microbianos hace más de 100 años, se hizo evidente la naturaleza biosedimentaria de estas comunidades microbianas; por ejemplo, Fenchel et al. (1998) reportan que de manera independiente Hofman y Ørsted describieron los extensos y coloridos sedimentos del Mar Wadden en Alemania (Fenchel et al., 1998); adicionalmente cuando Black (1933) describió los carbonatos estromatolíticos de las Bahamas, los interpretó como resultado de los cambios anuales en las tasas de sedimentación y de la zona de intermareas, apreciando su naturaleza biogénica. Hoy se sabe que los tapetes microbianos se componen de diversas y variadas comunidades de microorganismos que proliferan bajo condiciones ambientales que abarcan un amplio espectro de sustratos, $\mathrm{pH}$, temperatura y/o salinidad (Stal et al., 1995; Costerton et al., 1995; Stolz, 2000). Los tapetes ostentan característicamente una estratificación milimétrica que es interpretada como la consecuencia estructural del crecimiento y de un intercambio dinámico de nutrientes y material que difunde tanto horizontal como verticalmente (van Gemerden, 1993; Stal, 1995; van der Meer et al., 2005). Además de ésta estratificación física y biogeoquímica, los tapetes microbianos también se caracterizan por contener partículas sedimentarias y minerales, principalmente carbonato de calcio, incluidos dentro de la estructura tridimensional del tapete. A su vez, la matriz extracelular conformada por material polimérico conocido por sus siglas en inglés como EPS (extracelular polymeric substances), promueve la estabilización de sedimentos (Gerdes et al., 1993), su litificación (Reid et al., 2000) y su eventual incorporación en el registro fósil. Dicha incorporación se ha preservado en forma de microbialitas, que son depósitos organosedimentarios fósiles y recientes construidos por comunidades microbianas bentónicas (Burne y Moore, 1987). Es decir, los precursores de las microbialitas se van formando por el establecimiento de tapetes microbianos, principalmente cianobacterias (Awramik y Margulis, 1977), que unen, atrapan y precipitan partículas sedimentarias. En ambientes modernos las cianobacterias son los componentes 
volumétricamente importantes y los más estudiados. Aunque actualmente la ocurrencia de microbialitas es más frecuente en ambientes continentales (Gischler et al., 2008), la formación de tapetes microbianos es igualmente activa tanto en ambientes continentales como marinos, especialmente en aquellos ambientes donde prevalecen condiciones extremas o especiales. Por consiguiente, los tapetes microbianos constituyen excelentes análogos modernos de las microbialitas primitivas. Aún más, muchas de las interacciones microbio-mineral que ocurren apenas en unas cuantas micras del tapete microbiano pueden quedar preservadas a nivel morfológico, mineral, molecular y químico, por lo que los tapetes microbianos constituyen una auténtica fuente de biosignaturas microbianas (Chacon et al., 2010).

Un buen ejemplo de tapetes microbianos constituidos por cianobacterias y otros microorganismos que proliferan bajo condiciones ambientales mesófilas es el manantial sulfuroso conocido como Baño San Ignacio (BSI), situado en el municipio de Linares, Nuevo León. Esta localidad es un área natural protegida que además de albergar especies de flora y fauna endémicas, alberga diversas comunidades de microorganismos en forma de tapetes microbianos asociados a la precipitación de carbonato y cuyas aguas geotermales tienen $\mathrm{pH}$ neutros. Además de servir como una localidad para explorar interacciones ecológicas microbianas, el BSI constituye también un sitio con un alto potencial astrobiológico en cuanto a la preservación de biosignaturas. Este trabajo describe por vez primera las características biosedimentológicas más generales de los tapetes microbianos del BSI.

\section{Localidad de estudio}

El BSI es un manantial montañoso $\left(24^{\circ} 51^{\prime} 51^{\prime \prime} \mathrm{N}\right.$, $99^{\circ} 20^{\prime} 05^{\prime} \mathrm{W}$ ), localizado $23 \mathrm{~km}$ al este de la ciudad de Linares, Nuevo León, en el noreste de México (Figura 1 A). Aunque el BSI sólo cubre una pequeña área de la superficie vegetal terrestre, su contribución a la biodiversidad regional es significativa. Los pantanos del BSI contienen una flora y fauna dependientes de estas aguas subterráneas. Esta región comprende 4225.4 ha, incluyendo un manantial hidrotermal de aguas azufrosas que sirve de hábitat por lo menos a 5 especies de peces endémicos. Dicho manantial se encuentra enclavado en un pantano de aproximadamente 450 ha, cuyas condiciones de alta humedad en el suelo han permitido el desarrollo de un pastizal natural. Asimismo, en los márgenes meridionales del pantano, se desarrolla una comunidad de matorral espinoso tamaulipeco en buen estado de conservación (Cantú et al., 2001). Desde el año 2000 el Baño de San Ignacio fue declarado como una zona protegida por parte del Gobierno del Estado de Nuevo León (SEDUOP/FCF-UANL, 2000), y decretada oficialmente como una zona sujeta a conservación ecológica el 24 de noviembre de 2000 (POENL, 2000). Posteriormente, en
2009 fue declarado por sus características excepcionales, como un humedal de categoría RAMSAR (SEMARNAT, 2010), es decir, como un ecosistema de humedal de gran relevancia internacional para la conservación de la biodiversidad y bienestar de la comunidad humana, de acuerdo a la descripción dada por la comisión nacional de áreas naturales protegidas.

El BSI se ubica dentro de un área cuya superficie es de $\sim 5 \mathrm{~km}^{2}$ aproximadamente (Figura 1 B) y pertenece a un tipo de manantial denominado manantial de montículo, definido como un cuerpo central de agua, con un margen externo de canales y vegetación, un canal de flujo y capas sucesivas de carbonatos (Blinn et al., 1994; Mudd, 2000). En este caso, el agua subterránea alcanza la superficie elevándose a través de una fractura natural, en lugar de hacerlo a través de un agujero producido artificialmente. Este tipo de manantiales se forma por evaporación de aguas mineralizadas de manantiales artesianos, en los que ocasionalmente pueden ocurrir adiciones de material transportado por el viento en regiones áridas y semiáridas (Mudd, 2000). El montículo de manantial del BSI se localiza dentro de lo que constituye la Planicie Costera del Golfo de México (GMCP), que se extiende aproximadamente unos $1450 \mathrm{~km}$ a lo largo del Golfo de México, desde el estado de Tamaulipas (sobre la frontera de Texas) hasta los estados de Veracruz y Tabasco hasta la Península de Yucatán (De Cserna, 1989); dicha
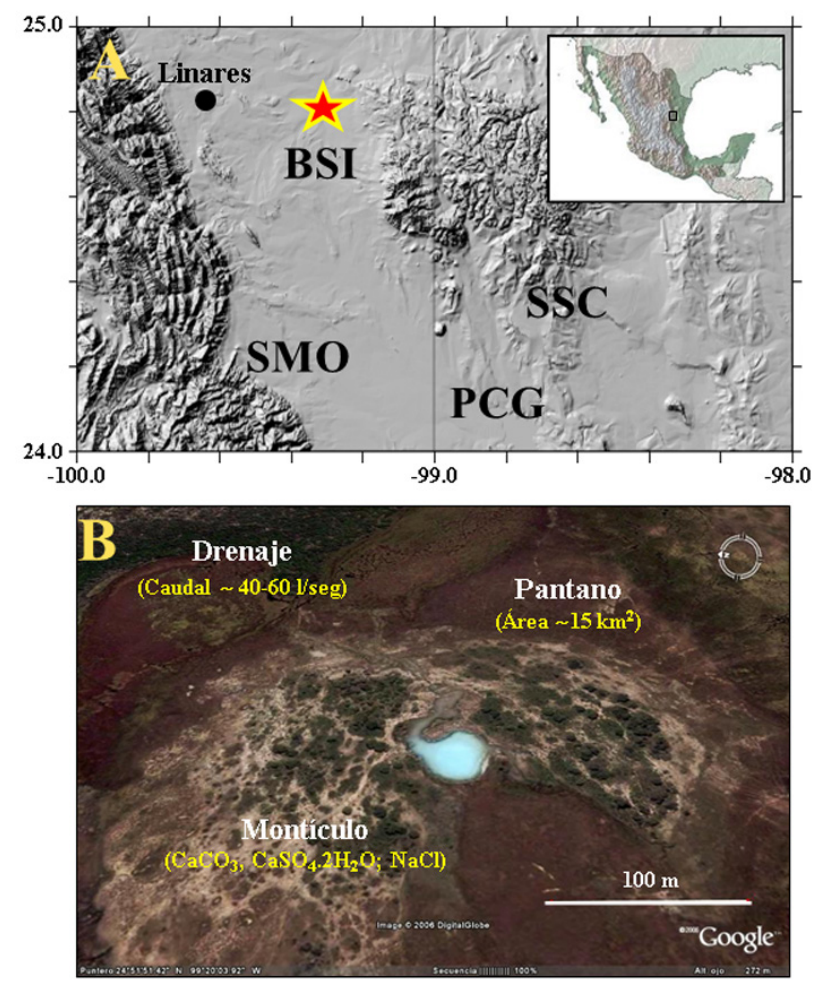

Figura 1. Localización del Baño San Ignacio en Linares, Nuevo León, México. (A) Coordenadas geográficas de la localidad bajo estudio: BSI $=$ Baño San Ignacio $;$ SMO = Sierra Madre Oriental; SSC $=$ Sierra San Carlos; PCG = Planicie Costera del Golfo (B) Geomorfología general de la localidad BSI bajo estudio (modificada a partir de Google Earth). 
planicie está flanqueada en su sector occidental por la Sierra Madre Oriental (SMO), un cinturón de falla y cabalgadura de cinturón sedimentario (Goldhammer, 1999; ChávezCabello et al., 2004), y hacia el sector este por la Sierra de San Carlos relacionada al magmatismo (Treviño-Cázares et al., 2005). El manantial hidrotermal BSI tiene forma de una laguna semicircular (Anderson, 1984) y ocupa una superficie de aproximadamente $2500 \mathrm{~m}^{2}$, exhibiendo una profundidad máxima de $7.5 \mathrm{~m}$ en forma de cono invertido y truncado, conformado por limos y carbonatos en suspensión (condición de fluidez) por la presión del agua saliente de los poros. Las unidades sedimentarias de basamento expuestas en la superficie del área estudiada pertenecen a sedimentos de las formaciones San Felipe y Méndez y corresponden al Cretácico Superior de la Sierra Madre Oriental. La Formación San Felipe (Turoniano-Coniciano) consiste de 110 a 150 m de estratificación delgada laminar con calizas de color gris pálido, interestratificadas con lutitas, porcelanitas (carbonatos silicificados), y con capas de ceniza volcánica alterada (Seibertz, 1998; Sohl et al., 1991; Garza-Castillo, 2006). La Formación Méndez (CampanianoMaastrichtiano), constituida por lutitas frágiles oscuras, con coloraciones verdosas a negras e intercalaciones menores, descansa concordantemente a la Formación San Felipe y está bien expuesta en el área bajo estudio. Aunque López-Ramos (1982) reporta un diámetro máximo de $\sim 1500$ m para esta unidad, en el área del BSI aparece como un estrato plegado de estratificación delgada. Adicionalmente la localidad BSI está rodeada por sedimentos recientes de aluvión y travertino que derivan de la formación San Felipe.

La geología regional del BSI incluye las planicies del Golfo de México (GMCP), característicamente cubierta por largos surcos de terrazas fluviales y lacustres del Terciario-Cuaternario originadas en la boca de los cañones de la SMO, con sistemas tributarios de grava provenientes de la Sierra San Carlos (SSC) (Ruiz-Martínez y Werner, 1997). Los sedimentos fluviales consisten de una secuencia de, por lo menos, cinco terrazas arriba del nivel reciente del río causado por los cambios periódicos y/o cíclicos, inducidos climáticamente entre la acumulación y la erosión durante los eventos de un levantamiento más o menos constante (Ruiz, 1990). Hidrogeológicamente el montículo de BSI se localiza en el sector noreste de la subcuenca de Camacho (cuya área aproximada es de $\sim 1529 \mathrm{~km}^{2}$ ) con una precipitación anual promedio de $\sim 70 \times 106 \mathrm{~m}^{3}$ (Secretaría de Programación y Presupuesto, 1993). Los trabajos realizados por Barbarín et al. (1988), Hoffmann et al. (1992), Benítez González (1997) y por Garza-Castillo (2006) reportaron un $\mathrm{pH}$ neutro $(\sim 7.5)$, temperaturas entre $36{ }^{\circ} \mathrm{C}$ y $38^{\circ} \mathrm{C}$, $\mathrm{y}$ un alto grado de mineralización (entre los $4300-4900$ $\mathrm{mg} / \mathrm{l}$; y una conductividad aproximada de $\sim 6.4 \mu \mathrm{S} / \mathrm{cm})$. La composición química está dominada por sulfatos $\left(\mathrm{SO}_{4}{ }^{-2}\right.$ $=900-1300 \mathrm{mg} / \mathrm{l})$, cloruros $\left(\mathrm{Cl}^{-}=1400-1700 \mathrm{mg} / \mathrm{l}\right)$, sodio $\left(\mathrm{Na}^{+}=300-900 \mathrm{mg} / \mathrm{l}\right)$, y calcio $\left(\mathrm{CaCO}_{3}=700-\right.$ $1000 \mathrm{mg} / \mathrm{l})$. De acuerdo al modelo conceptual de facies hidrogeoquímicas para aguas subterráneas de la subcuenca de Camacho (Garza-Castillo, 2006) y al modelo de flujo de gravedad regional propuesto por Toth (1999), el manantial de montículo de BSI podría representar la manifestación de un flujo regional de aguas subterráneas, caracterizado por un $\mathrm{pH}$ cercano a la neutralidad, un potencial redox positivo y un sistema altamente mineralizado con una química tipo $\mathrm{Na}^{+}-\mathrm{Ca}^{+2}-\mathrm{Cl}^{-}-\mathrm{SO}_{4}{ }^{-2}$. Anderson y Aguilera (1986) han sugerido que la temperatura en el depósito de montículo de BSI está asociada al efecto de gradiente geotérmico regional $\left(\Gamma \sim 25^{\circ} \mathrm{C} / \mathrm{km}\right)$, mientras que la mineralización puede ser el resultado de la interacción agua-roca con las rocas sedimentarias mesozoicas de la SMO (Goldhammer, 1999).

\section{Metodología}

El área de estudio está constituida por una fuente somera pero sumergida que fluye a lo largo de una distancia de 30 $\mathrm{m}$ aproximadamente. Existe un gradiente de temperatura que se angosta hacia un canal lineal principal (Figura 2 A). Las observaciones de campo incluyen un muestreo estacional en invierno y verano de 2009 a 2012 siguiendo el desarrollo de tapetes microbianos a lo largo del gradiente en los que se determinó el pH con papel pH-metro, así como la temperatura y las dimensiones de los tapetes. El material identificado incluye muestras representativas de los tapetes microbianos bentónicos adheridos a la roca calcárea. Dichas muestras de tapetes fueron tomadas como rebanadas completas (con un tamaño aproximado de $10 \mathrm{~cm}$ de ancho por $7 \mathrm{~cm}$ de largo) que inmediatamente fueron guardadas en refrigeración a $4{ }^{\circ} \mathrm{C}$ hasta su análisis en el laboratorio. La gran mayoría de muestras fueron analizadas sin aditivos ni fijadores químicos. Otro lote de muestras fue liofilizado y guardado para futuros análisis, mientras que un tercer lote se conservó en formaldehído al 4 \% como reserva. Se prepararon láminas delgadas del contenido biológico de los tapetes microbianos previa disección bajo el microscopio. La identificación del material fue basada únicamente en caracteres morfológicos y de acuerdo a los manuales tradicionales de ficología (Geitler, 1932; Anagnostidis y Komárek, 1988; Komárek y Anagnostidis, 1999; Komárek y Golubic, 2005). Las observaciones se llevaron a cabo en un microscopio Olympus BX51 equipado con una unidad de cámara de contraste diferencial interferencial DIC y una cámara digital (Facultad de Ciencias, UNAM). También se prepararon muestras petrográficas del travertino asociado, algunas de las cuales también se observaron al SEM en un microscopio de emisión de campo SEM-Hitachi 4700-II, con un voltaje de $1.5-15 \mathrm{kV}$, como servicio externo. Algunas de las muestras analizadas por microscopía electrónica de barrido (SEM) se cubrieron con oro y fueron observadas en un equipo JEOL 6301F; otras veces se analizaron muestras refrigeradas después de secarse a temperatura ambiente y sin baño de oro. Se utilizó la Microsonda Electrónica de Barrido JEOL 8900R WD/ED en el Instituto de Geofísica, UNAM. Las imágenes de autofluorescencia se obtuvieron 

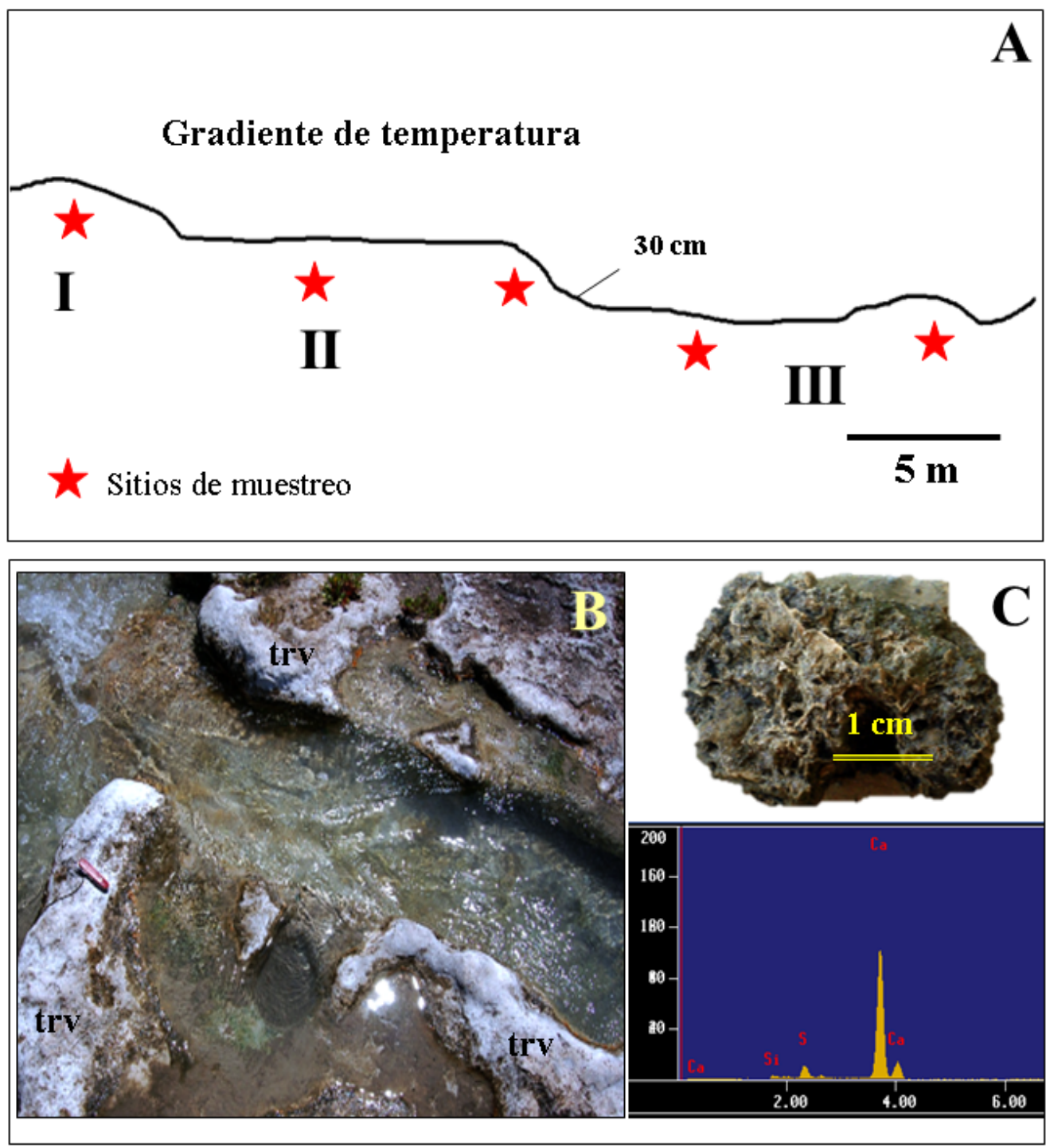

Figura 2. Croquis del manantial de BSI. Los numerales romanos señalan los sitios de muestreo: I = zona de eflujo; II: facies proximales y área de muestreo para este análisis; III: facies distales. (B) Travertinos (trv) asociados a los tapetes microbianos del BSI. (C) Muestra de mano de travertino y su composición detectada por EDS.

mediante un Microscopio Confocal FV10 (FluoView FV10i, Olympus) en el Instituto de Fisiología Celular, UNAM (servicio externo).

\section{Resultados}

El BSI representa un manantial sulfuroso con fluctuaciones de $\mathrm{pH}$ entre 7 y 7.6, y con temperaturas alrededor de LOS $36.4^{\circ} \mathrm{C}$ en verano y alrededor de $31^{\circ} \mathrm{C}$ en invierno. Aunque la temperatura es aproximadamente constante a lo largo del canal principal, existe un gradiente muy tenue desde la fuente del manantial, con temperaturas alrededor de los $37.5^{\circ} \mathrm{C}$ hasta los $35^{\circ} \mathrm{C}$ en las facies distales (Figura 2 A). Los resultados obtenidos a lo largo de este estudio muestran que el desarrollo de tapetes microbianos en los márgenes del manantial de BSI es constante a lo largo de los diferentes periodos estacionales, mientras que las terrazas que bordean el canal están formadas mayoritariamente por travertino asociado (Figuras $2 \mathrm{~B}$ y C). Los travertinos exhiben diferentes grados de calcificación superficial, y en algunos casos, ésta es correlacionable con el desarrollo de tapetes microbianos, los cuales pueden encontrarse como tapetes estratiformes o como tapetes flotantes. La persistencia de tapetes microbianos se ha monitoreado por varios años y en las diferentes estaciones del año, por lo que podría decirse que son perennes o se forman continuamente en cada punto del transecto.

\subsection{Geoquímica}

El Baño San Ignacio es una manifestación de agua 
termal en cuya parte norte y noroeste posee un vertedero natural que alimenta al pantano de la zona marginal. El sistema, en su conjunto, puede ser considerado como un manantial de montículo (mound spring), ya que incluye un cuerpo central de agua, un borde de juncos y vegetación, un canal de flujo y capas sucesivas de carbonatos, yeso y halita (Blinn et al., 1994; Mudd, 2000). Las especies iónicas predominantes en las aguas del BSI son $\mathrm{SO}_{3}, \mathrm{CaO}$ y $\mathrm{SO}_{3}$, y en cantidades mucho menores $\mathrm{MnO}, \mathrm{Na}_{2} \mathrm{O}$ y $\mathrm{Fe}_{2} \mathrm{O}_{3}$. Los análisis hidrológicos publicados (Barbarín et al., 1988; Hoffmann et al., 1992; Garza-Castillo, 2006) indican que el BSI presenta una hidrogeoquímica muy particular, caracterizada por un $\mathrm{pH}$ neutro a ligeramente alcalino (7.0 - 8.0), una relativa alta temperatura $\left(\mathrm{T}=33-35^{\circ} \mathrm{C}\right) \mathrm{y}$ altas conductividades $(6300-7940 \mu \mathrm{S} / \mathrm{cm})$ como un reflejo de los altos contenidos de sólidos disueltos (4300 - 4900 $\mathrm{mg} / \mathrm{l})$. El análisis geoquímico para el BSI derivado de éste y de previos estudios resulta en la distribución geoquímica ilustrada en el Diagrama de Durov (Hem, 1985), que muestra una comparación con la química observada en el agua superficial y subterránea de las zonas aledañas (Figura 3), como son la Presa Cerro Prieto (PCP) y la cuenca del Río Pablillo (CRP). A diferencia del BSI, la hidrogeoquímica en estos otros sitios se caracteriza por ser de dominio $\mathrm{Ca}$ $\mathrm{HCO}_{3}$ y $\mathrm{Ca}-\mathrm{HCO}_{3}-\mathrm{SO}_{4}$, con un $\mathrm{pH}$ neutro a ligeramente ácido $(6.5-7.0)$, así como temperaturas $\left(16-26^{\circ} \mathrm{C}\right) \mathrm{y}$ conductividades $(470-790 \mu \mathrm{S} / \mathrm{cm})$ relativamente bajas
(Rodríguez de Barbarín y Barbarín, 1993).

\subsection{Tapetes microbianos}

Los tapetes microbianos en el BSI exhiben dos morfologías principales: tapetes flotantes subesféricos de coloración anaranjada (con espesores de $3.5 \mathrm{~cm}$ y diámetros entre 10 y $30 \mathrm{~cm}$ ), y tapetes estratiformes adheridos al sustrato, de aproximadamente $50 \mathrm{~cm}$ de longitud distribuidos linealmente sobre un sustrato calcáreo de travertino y con un espesor constante de $5 \mathrm{~cm}$ (Figuras 4 A y B). Mientras que en la parte central del manantial los tapetes flotantes son concéntricos y bien laminados, en las partes distales los tapetes tienden a ser más pegajosos y menos coloridos. En este trabajo se reportan los análisis de los tapetes adheridos al sustrato rocoso, por ser tapetes bentónicos y los más persistentes en invierno y primavera. Además, el travertino asociado muestra una calcificación intensa en la interfase donde se forman los tapetes adheridos al sustrato. Inclusive en la interfase agua-sedimento de las zonas más distales del manantial también se observa la formación de tapetes estratificados sin forma definida con un perfil verdoso en la parte superior y con bordes tenues color naranja (Figura 5A). Dentro de la estratificación macroscópica del tapete se identificaron cuatro zonas principales cuyas texturas están representadas en la secuencia vertical de la Figura 5: (Zona I) la capa superior corresponde a una capa irregular

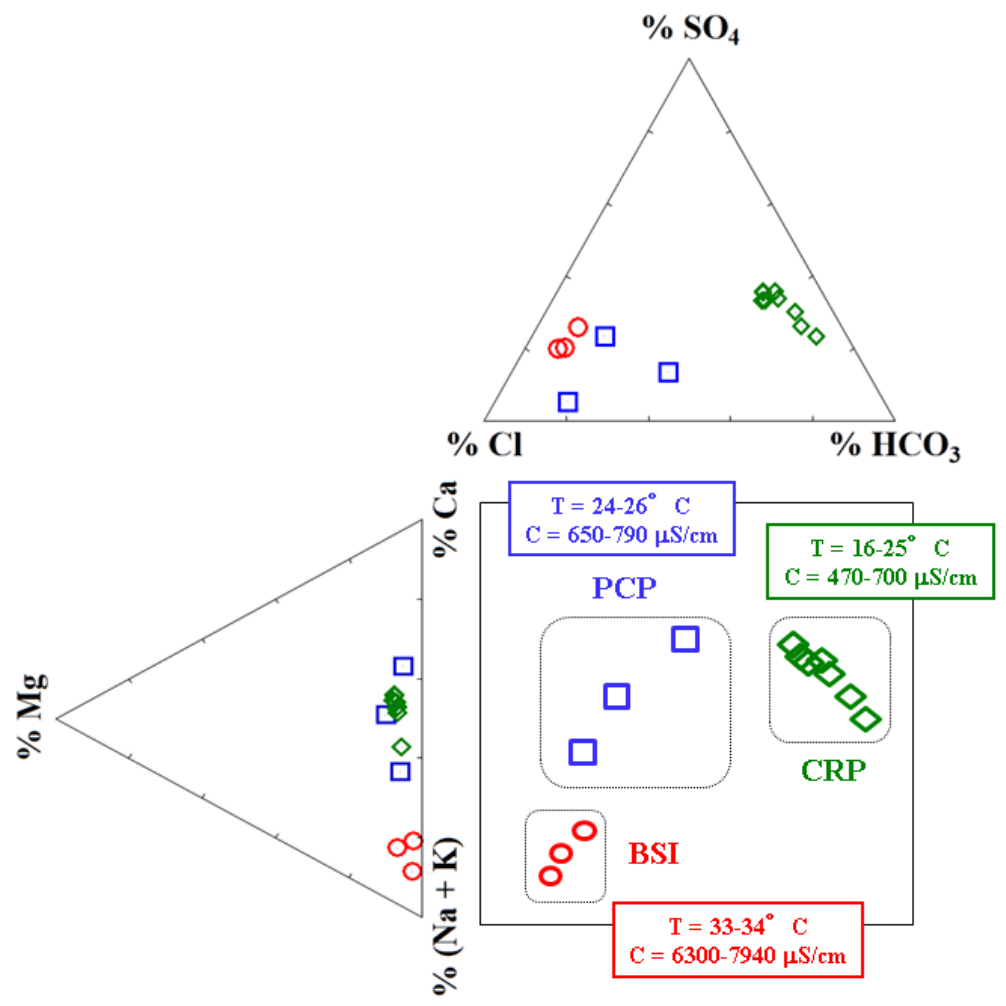

Figura 3. Clasificación del agua hidrotermal de acuerdo al diagrama de Durov (Hem, 1985) utilizando datos geoquímicos derivados del BSI. Nótese la química del agua en BSI en contraste con la química observada en el agua superficial y subterránea de las zonas aledañas en la Presa Cerro Prieto (PCP) y en la cuenca del Río Pablillo (CRP). 


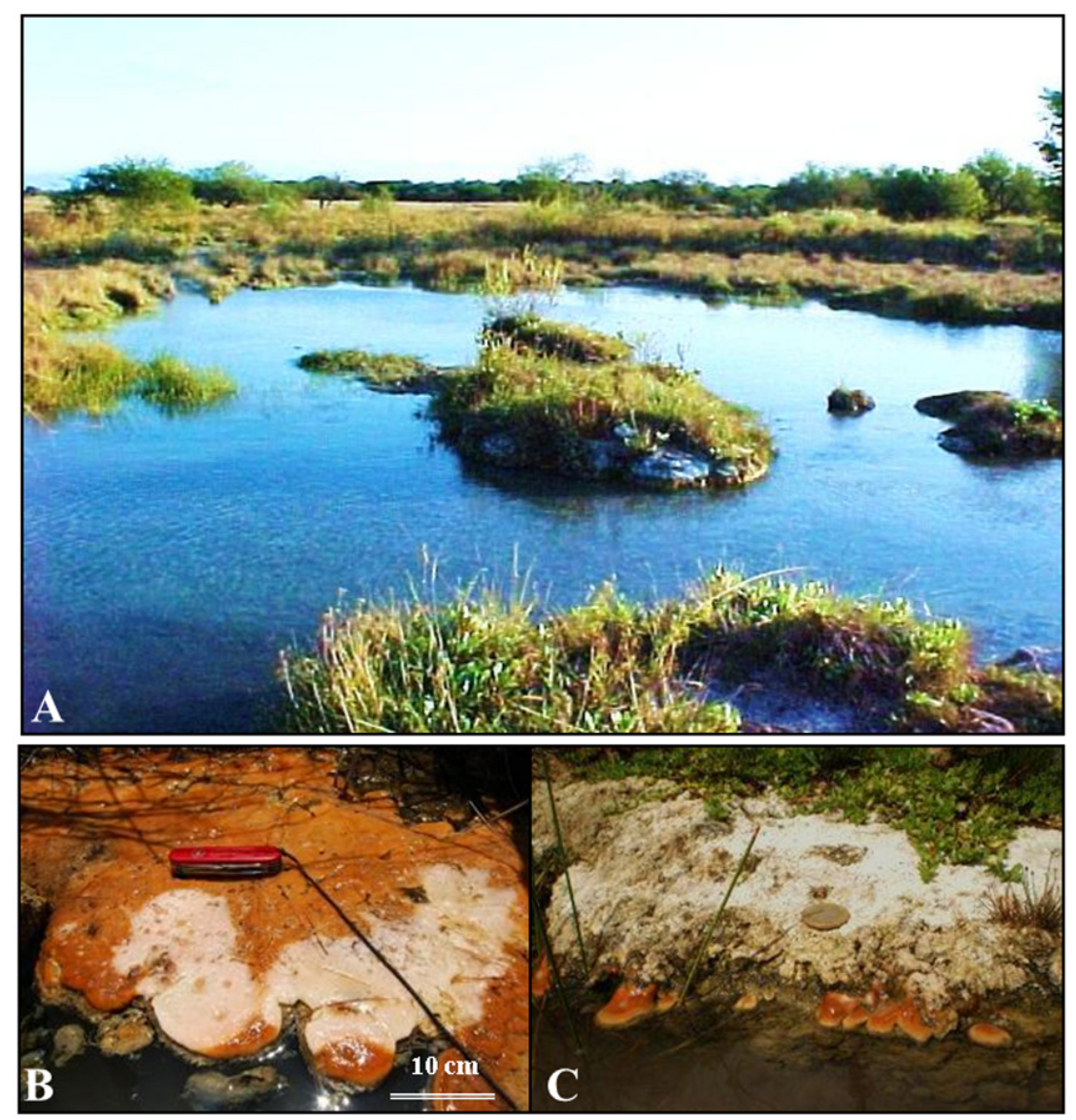

Figura 4. Forma y dimensiones de los tapetes microbianos in situ que caracterizan la zona somera del manantial en BSI. (A) Zona somera del manantial de la localidad BSI. (B) Tapetes circulares que muestran precipitación de $\mathrm{CaCO}_{3}$, principalmente en el centro del tapete. (C) Tapetes estratiformes a lo largo del canal de flujo en BSI.

relativamente gruesa y oscura (de espesor y texturas lateralmente variables), seguida por una zona verdosa bien definida de más de $0.5 \mathrm{~cm}$ de espesor (Zona II), donde abundan poblaciones filamentosas de cianobacterias y material particulado en contacto con una subcapa color rojizo a café; posteriormente hay una tercera zona central de aproximadamente $2 \mathrm{~cm}$ de espesor (Zona III) caracterizada por una laminación regular y homogénea de coloraciones claras, cafés y verdosas donde abundan diatomeas y cianobacterias. Dicha zona está organizada en laminaciones finas y claras de 100 a $500 \mu \mathrm{m}$ de espesor que alternan con laminaciones oscuras de 300 a $500 \mu \mathrm{m}$ de espesor y con una cierta convexidad, siendo más pronunciada mientras más fina es la laminación. También se observa la presencia de inclusiones cristalinas relativamente gruesas en la laminación y de cristales pequeños y uniformes que se ordenan entre los estratos cafés de la parte central e inferior del tapete. La parte inferior de los tapetes (Zona IV) muestra una microcapa más oscura de textura aterciopelada que limita con una capa de grano grueso sin estructura. Las zonas del tapete detectadas por fluorescencia (Figura 5B) muestran las diferencias en la distribución y abundancia relativa en la microbiota a lo largo del tapete, siendo la Zona II la que tiene un mayor contenido de microorganismos y la Zona III la que tiene mayor contenido de calcita. Cabe mencionar que estos tapetes mostraron tener una alta fluorescencia natural en cualquier punto del transecto. Aunque los tapetes microbianos del BSI ostentan un aspecto y textura aparente de hongo, los microorganismos identificados en los tres primeros centímetros del tapete corresponden a morfotipos de cianobacterias, a diatomeas pennadas (en particular de los géneros Amphora y Nitzschia), y en una menor proporción a clorofitas y otras eubacterias no identificadas.

\subsection{Biosedimentos y microorganismos asociados}

La zona analizada del tapete a nivel microscópico se muestra en la Figura 6. La parte más densa del tapete corresponde a la interfase entre la zona 1 y 2 del perfil vertical del tapete. Dicha zona está compuesta por una malla filamentosa constituida por cianobacterias aparentemente del mismo morfotipo y sedimentos subredondeados relativamente grandes y aislados (Figuras 6 A-C); menos frecuente es la ocurrencia de calcita euhedral (de $20 \mu \mathrm{m}$ de espesor) en asociación con morfotipos cocoides y frústulas de diatomeas, principalmente del género Amphora 


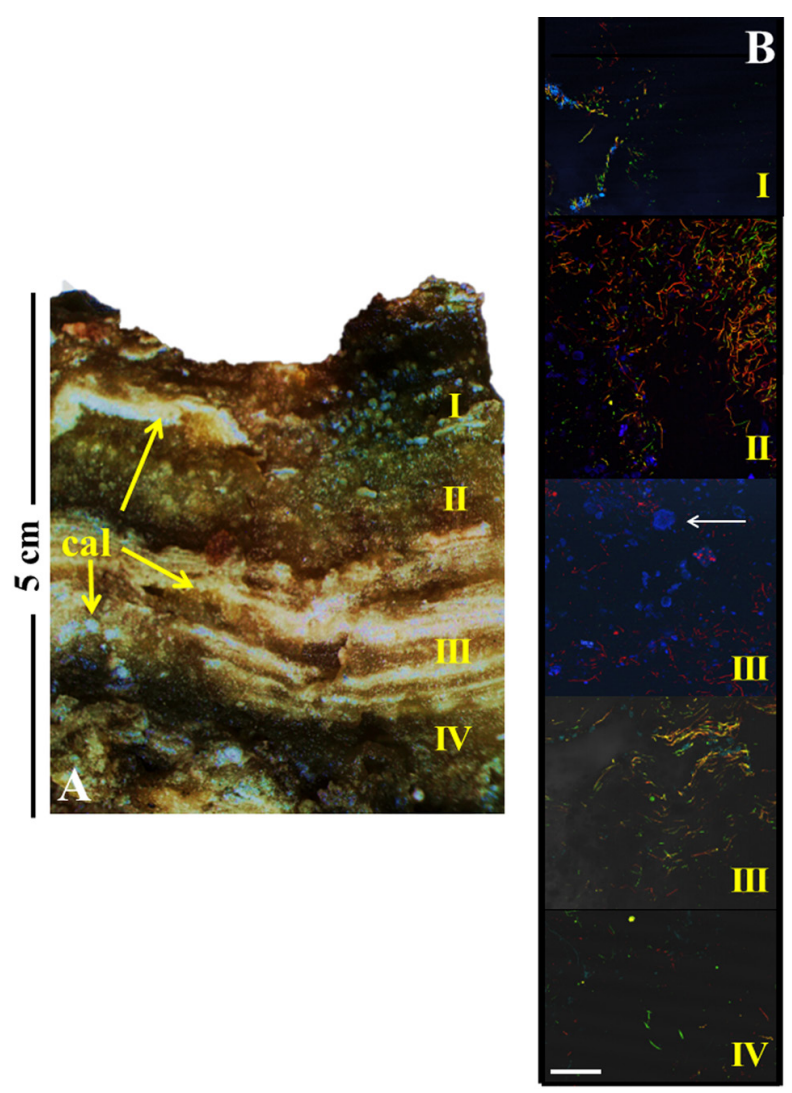

Figura 5. (A) Corte transversal de un tapete microbiano representativo del BSI irregularmente laminado en bandas verdes y blancas, y mineralizaciones irregulares en zonas discretas (flechas). (B) Fotomicrografía de la autofluorescencia natural del perfil vertical del tapete que muestra una zonación macroscópica. La presencia de bacterias sulfato-reductoras es sólo inferida. Escala en $\mathrm{B}=100 \mu \mathrm{m}$.

y Nitzschia (Figura 6D), alineadas subparalelamente a sedimentos redondeados de tamaños variables y asociadas al material polimérico (Figuras 6 E y F). En la región central del tapete se identificaron poblaciones abundantes de clorofitas, entre las cuales también es posible distinguir algunas diatomeas (Figura 6G) y filamentos uniseriados de cianobacterias pertenecientes a Oscillatoriales (Figura $6 \mathrm{H})$. Incluso se observan capas paralelas conformadas por la alineación horizontal de materia orgánica y peloides (Figura 6I) en alternancia con capas claras. En el caso particular de algunos morfotipos filamentosos similares a Phormidium, la precipitación de calcita se observó ya sea como un recubrimiento uniforme a todo lo largo de un filamento, o bien, en forma de cristales aciculares asociados a materia orgánica (Figura $6 \mathrm{~J}$ ). También se detectó la presencia de abundantes filamentos cortos y pequeños (de aproximadamente $2 \mu \mathrm{m}$ de diámetro y más de $100 \mu \mathrm{m}$ de longitud) asociados a las cianobacterias filamentosas y hormogonios que podrían corresponder a microorganismos de bacterias azufrosas o inclusive a hifas derivadas de hongos (Figura 6K).

\subsection{Matriz Extracelular}

El tapete microbiano está estructurado por una malla orgánica irregular a la que se adhieren partículas sedimentarias y material polimérico, por lo que se presume la naturaleza cohesiva de la matriz extracelular (Figura 7A). Además de la alta porosidad en el interior de los tapetes del BSI, en otras regiones de la infraestructura orgánica se observa una textura microgranular heterogénea asociada a cianobacterias filamentosas y cocoides, así como a agregados subesféricos (Figura 7B). El área más estructurada del tapete corresponde a las zonas finamente laminadas, cuyas micrografías SEM exhiben una alineación paralela de fibras orgánicas a las que se adhieren precipitados de calcita y material orgánico más fino (Figura 7C). Los agregados subesferoidales (Figuras $7 \mathrm{~B}$ y D), las delicadas estructuras orgánicas rodeadas por calcita euhedral (Figura 7E) y la presencia de largas fibras poliméricas que unen diferentes tipos de precipitados (Figura 7F) se encuentran entre los biosedimentos más característicos de los tapetes microbianos del BSI. Existen fibras orgánicas extensas que muestran una asociación estrecha con diatomeas en áreas con gran cantidad de biofilm (Figura 7G), y donde es posible observar fibras que se proyectan a partir de la parte apical de una diatomea y están asociadas a material polimérico extracelular (EPS) y precipitados amorfos.

\section{Discusión}

A diferencia de muchos tapetes microbianos que se forman en ambientes sedimentarios de condiciones extremas, los tapetes microbianos del BSI pertenecen a un ambiente moderado y de condiciones ambientales muy neutras. Es notable que aunque los tapetes del BSI ostenten una apariencia similar en textura, coloración y consistencia a tapetes derivados de ambientes extremos, como los tapetes microbianos de Guerrero Negro, Baja California (Hoehler et al., 2001), los tapetes microbianos de la laguna costera de Lagoa Vermelha en Brasil (Spadafora et al., 2010) o los tapetes hipersalinos del atolón Kiritimati (Schneider et al., 2013), los valores de $\mathrm{pH}$ y temperatura reflejan condiciones más bien mesófilas; esto sugiere que dichos parámetros ambientales no son determinantes en el aspecto y la estructura de los tapetes del BSI. Probablemente, más que el $\mathrm{pH}$ y la temperatura, el alto grado de mineralización de las aguas del BSI, ricas en iones, sean las que ejerzan una influencia más directa en el gradiente geoquímico y por consiguiente, en la diferenciación textural de los tapetes a nivel de microescala. Es decir, la geoquímica ambiental impacta en la actividad microbiana en estos ambientes, sobre todo considerando las distancias relativamente cortas (en metros) respecto al centro de eflujo y una turbulencia relativamente baja en el manantial del BSI. Estos resultados contrastan con algunos ejemplos de manantiales con un mayor nivel de energía y turbulencia, y frecuentemente de 


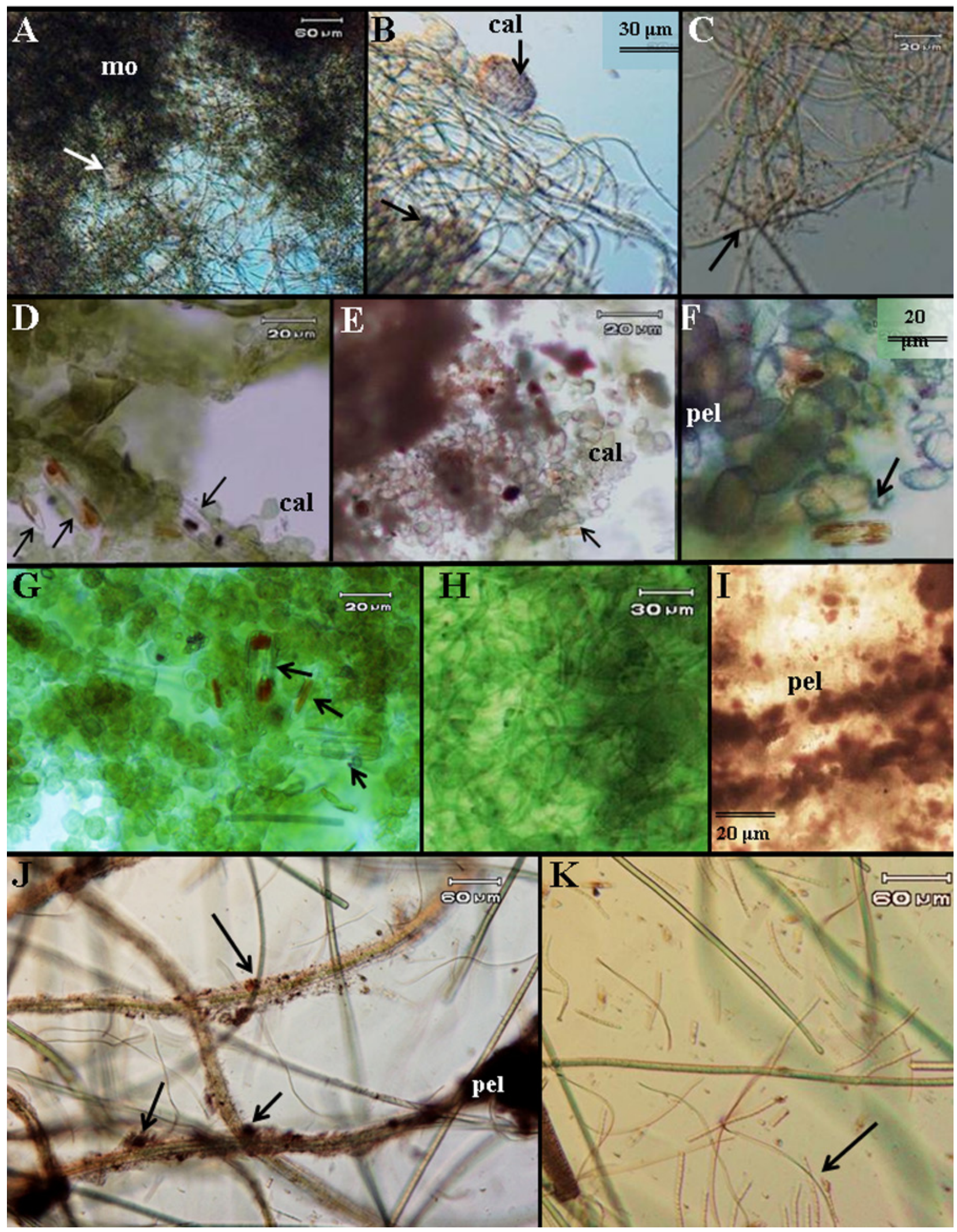

Figura 6. Biosedimentos y microbiota representada en el BSI. (A-C) Malla de poblaciones filamentosas, principalmente cianobacterias asociadas a materia orgánica (mo), donde se identificaron partículas sedimentarias (calcita, cal) de diferentes tamaños (flechas). (D-F) Las diatomeas (flechas) se alinean entre sedimentos subredondeados, materia orgánica e inclusiones peloidales. (G-H) Las partes centrales del tapete muestran poblaciones de clorofitas y poblaciones filamentosas de cianobacterias. (I) Las laminaciones claras alternan con peloides (pel) y micropeloides alineados. (J) En algunos filamentos se observó la precipitación lineal de calcita euhedral. $(\mathrm{K})$ Otras poblaciones de filamentos pequeños, cortos y delgados asociados a los filamentos uniseriados son comunes. 


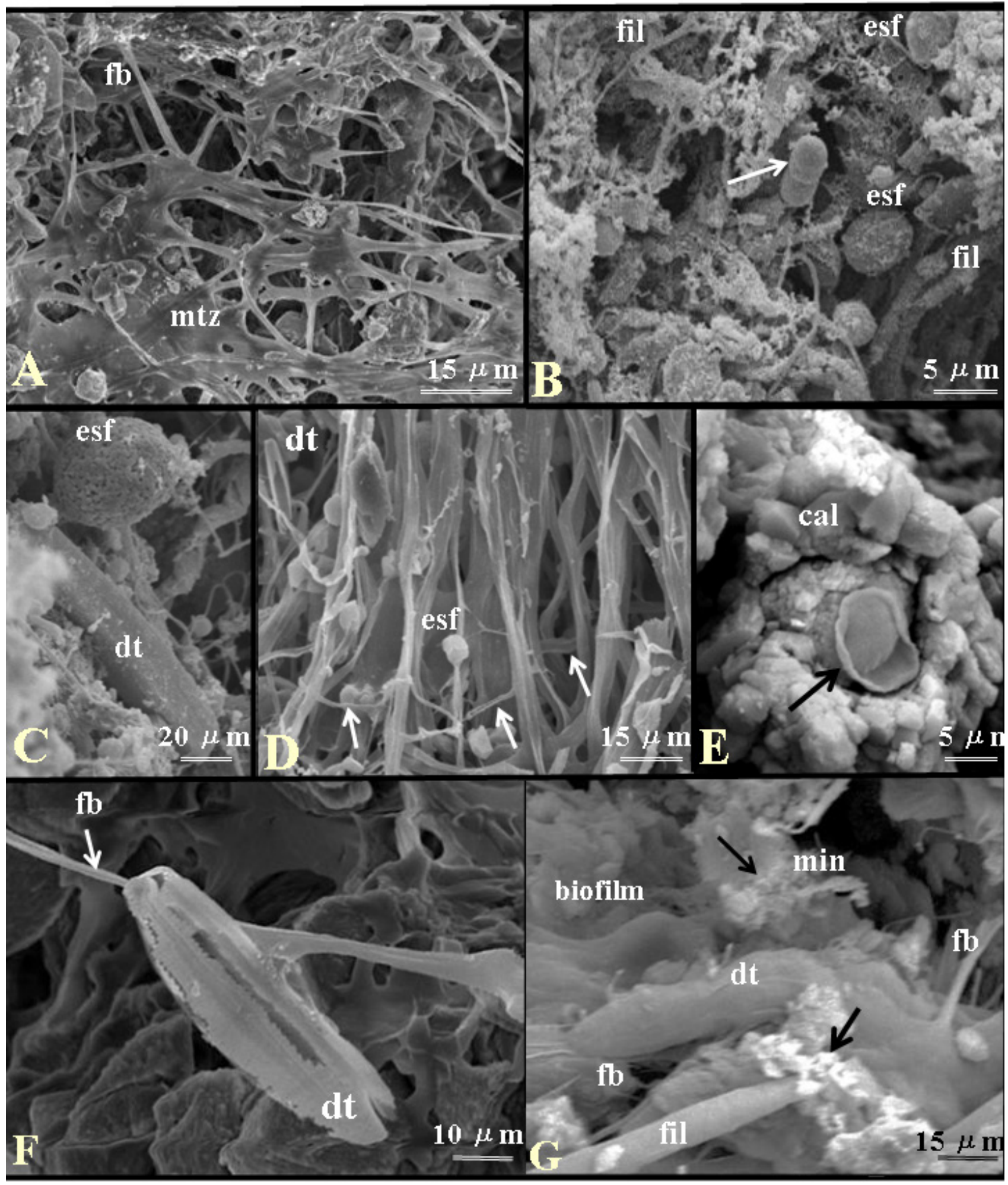

Figura 7. Estructura interna de un tapete microbiano de BSI. (A-C) La red tridimensional de la matriz extracelular (mtz) contiene diversos filamentos (fil) y cocoides cianobacterianos (flecha en B), frústulas penadas de diatomeas (dt), así como esférulas (esf) como biosedimentos más comunes asociados a la matriz orgánica (flechas). (D) Típica estructura tridimensional del tapete del BSI que muestra el EPS formado por abundantes fibras poliméricas dispuestas verticalmente que aglutinan biosedimentos subesferoidales, así como pequeños puentes orgánicos horizontales (flechas). (E) Algunos biosedimentos característicos son las microestructuras de colapso de la célula apical (flecha) rodeada por calcita (cal) dispuesta radialmente. (F) Vista lateral de una frústula de diatomea adherida a largas fibras poliméricas (fb) del EPS en el interior del tapete microbiano. (G) Mineralización parcial del EPS (min) sobre biofilm asociado a diatomeas, filamentos y fibras poliméricas. 
alta salinidad, donde se forman tapetes morfológicamente similares a los del BSI en textura y coloración (Esteve et al., 1992; Spadafora et al., 2010), pero diferentes en el número y espesor de las capas. De acuerdo a la composición de las aguas superficiales (Figura 3), deberían de encontrarse muchos más minerales en la matriz extracelular de los tapetes, ya que la composición de las aguas superficiales indica una alta mineralización (Garza-Castillo, 2006); no obstante, la calcita asociada al biofilm es el único precipitado observado en los tapetes microbianos (Figuras 6 y 7). Al respecto se ha propuesto que el carbonato de calcio es promovido por la actividad metabólica de las comunidades microbianas que favorecen la precipitación (Dupraz y Visscher, 2005; Visscher y Stolz, 2005; Dupraz et al., 2009). La mineralización más abundante ocurre en la zona central del manantial y procede de forma gradual a lo largo del flujo, donde los tapetes muestran mayor grado de calcificación, y la presencia de calcita euhedral como cementante en espacios porosos. A nivel de la infraestructura microscópica, los tapetes muestran una calcificación diferencial, principalmente en zonas donde se detecta la presencia de diatomeas y donde la cantidad de fibras poliméricas es mayor.

En tapetes microbianos recientes se ha documentado la calcificación diferencial del EPS como una consecuencia termodinámica del gradiente de alcalinidad y de la cantidad del EPS producido por fotosíntesis y por la oxidación anaeróbica del sulfuro (Arp et al., 1999, Visscher et al., 2000; Dupraz y Visscher, 2005), ya que la desecación va concentrando los iones adsorbidos en el EPS (Arp et al., 1999; Braissant et al., 2003). En el caso del BSI no hay periodos marcados de inundación/desecación, sino un flujo constante de aguas mineralizadas. Además de cierto grado de calcificación externa e interna del tapete, algunas de las texturas presentes en los tapete de BSI también son similares a texturas y biosedimentos de microbialitas fósiles y recientes, como la malla tridimensional extendida (Figura 7A), las esférulas minerales de tamaño diverso (Figuras 7 A y D), las estructuras apicales de colapso (Figura 7E) y la precipitación puntual de aragonita sobre el EPS (Figura 7E).

Aunque los tapetes del BSI muestreados a lo largo del canal exhiben una precipitación heterogénea en la superficie (Figura 4), a nivel de estructura interna las texturas son homogéneas, aún en zonas donde la turbulencia es mínima (Figura 2, sitio III), pero a nivel individual la mineralización es extensa en las partes centrales de los tapetes. De acuerdo a Pentecost (2005) un factor determinante que promueve la precipitación de carbonatos es precisamente la turbulencia y la remoción fotosintética del $\mathrm{CO}_{2}$, si bien la precipitación de carbonatos es mayoritariamente abiogénica (Pentecost, 2003). Adicionalmente, en aguas saturadas con respecto al $\mathrm{CaCO}_{3}$, la constante evaporación promueve depósitos carbonatados mientras tiene lugar la bioprecipitación de carbonatos (Golubic, 1983, Pentecost et al., 2003; Della Porta, 2015).

Los resultados encontrados en el BSI indican que la mineralización del tapete microbiano es influenciada biológicamente y ocurre a través del atrapamiento y la unión cohesiva de partículas de carbonato. Es probable también que la precipitación puntual de calcita sea inducida biológicamente por el metabolismo microbiano, como en el caso de algunos filamentos de Oscillatoriales. En el caso de filamentos similares a Phormidium sp., se aprecia una distribución regular en la precipitación lineal de calcita (uniforme y del mismo tamaño) a lo largo del filamento (Figura 6K); inclusive la influencia del mucílago en la estabilización y unión de la calcita precipitada es evidente. Es decir, la mayoría de biosedimentos del BSI observados en la matriz orgánica de los tapetes precipitan por las condiciones termodinámicas del microambiente, mientras que la influencia biológica está determinada por la cantidad de biofilm que sirve como sitio de nucleación de calcita y/o de los iones de calcio adsorbidos al biofilm contribuyendo eventualmente a la precipitación (Braissant et al., 2003). La naturaleza cohesiva de las envolturas mucilaginosas de cianobacterias también es un factor esencial durante la acreción de éste tipo de comunidades bentónicas (Stoodley et al., 2002; Dillon y Castenholz, 1999), ya que el mucílago puede actuar como pegamento sedimentario que ayuda a la estabilización del tapete en contra de la erosión, lo que a su vez incrementa su potencial de preservación en el registro fósil (Noffke y Paterson, 2008). Aunque la ubicuidad de cianobacterias en travertinos se ha reconocido desde hace varios años (Pentecost, 1990; Chafetz y Buczynski, 1992, Jones y Renaut, 1996), su relación con microtexturas y biosedimentos en carbonatos está siendo investigada con mayor resolución sólo muy recientemente, sobre todo en ambientes de condiciones ambientales muy extremas; por tanto, localidades de condiciones intermedias y poco turbulentas como las que imperan en BSI podrían ser utilizados como referentes. En los tapetes asociados a travertinos del BSI, las cianobacterias son contribuyentes importantes de la matriz orgánica a la que se adhieren los sedimentos; aunque se reconoce que las cianobacterias tienen una influencia mínima en la precipitación de carbonatos (Pentecost, 2005; Golubic et al., 2008). En general, la infraestructura o textura de los carbonatos es impactada de manera significativa por procesos biológicos a diferentes escalas.

El hecho de encontrar gran cantidad de cianobacterias es común, ya que además de llevar a cabo la producción primaria por medio de la fotosíntesis, son pioneras colonizando sustratos. Muy probablemente existen componentes heterotróficos y microaerofílicos de otras poblaciones bacterianas no detectadas que seguramente también forman parte importante del gradiente biogeoquímico en los tapetes del BSI. El hecho de que las diatomeas se encuentren alineadas en cada capa de los tres centímetros superiores del tapete, y en asociación directa tanto con otras poblaciones microbianas (filamentos y clorofitas), así como con sedimentos del mismo tamaño (Figuras 6 $\mathrm{E}, \mathrm{F}, \mathrm{G}, \mathrm{y} \mathrm{J})$ puede ser relevante a nivel estructural del 
tapete. Además, las diatomeas alternan espacialmente con calcita y con cianobacterias en la zona central del tapete, la cual corresponde también a la zona más estructurada. Las diatomeas forman asociaciones con cianobacterias y con otras bacterias (Figura 6K), incluyendo filamentos cortos no identificados así como muchas otras poblaciones bacterianas, entre ellas bacterias sulfatoreductoras que deben identificarse por métodos moleculares. Asociadas a las diatomeas abundan fibras de mucopolisacáridos como agentes cohesivos de la matriz extracelular; dichas fibras poliméricas contienen sedimentos así como frústulas y esférulas orgánicas de diferentes diámetros, como se ilustra en la Figura 7. Las diatomeas tienen también una relación estrecha con la materia orgánica, al menos de manera superficial; aunque no es claro que influyan en la precipitación de calcita, es probable que en el proceso de atrapamiento y unión mineral, sí. Estas fibras orgánicas presentan un arreglo muy estructurado que pudiera ser importante en la laminación del tapete microbiano y en su resistencia a la disrupción física. Por su abundancia, su distribución y por los biosedimentos asociados a ellas, las diatomeas son importantes tanto a nivel estructural como en el aporte de material polimérico del tapete. Inclusive las diatomeas se reportan continuamente en la gran mayoría de microbialitas modernas asociadas a la precipitación de carbonato de calcio (Winsborough y Golubic, 1987; Winsborough, 2000; Chacon et al., 2011; Della Porta, 2015). Pero aun cuando la presencia de diatomeas en tapetes microbianos es común, sobre todo en microbialitas de ambientes modernos (Awramik y Riding, 1988; Winsborough et al., 1994; Winsborough, 2000; Gischler et al., 2008; Chacon et al., 2011; Della Porta, 2015) su papel en los procesos de atrapamiento, precipitación y/o estabilización de sedimentos continúa siendo poco reconocido. Finalmente, como organismos fotosintéticos, las diatomeas son componentes clave en la caracterización de tapetes microbianos, pues además de su papel en la estabilización y estructura del tapete, se pueden utilizar como indicadores batimétricos de la productividad y en la reconstrucción de paleoclimas (Bonny y Jones, 2008).

\section{Conclusiones}

Aunque el BSI es un ambiente mesófilo con un pH y temperaturas moderadas, las características especiales respecto a la hidrogeoquímica del BSI son críticas para el desarrollo del pantano y de las especies que en él habitan, incluyendo la vida microbiana. Si bien los precipitados minerales en BSI muestran una distribución heterogénea en la matriz extracelular, la mayoría se concentra en la parte central de los tapetes en una zona donde la laminación es más uniforme y fina. En estos tapetes se observó que la calcificación no está asociada directamente a la influencia de un sólo tipo de filamentos, y que la cantidad de biofilm y la concentración de poblaciones filamentosas influye más en procesos de unión y atrapamiento de precipitados carbonatados.

La caracterización de tapetes microbianos derivados de ambientes continentales es importante para identificar los factores ecológicos determinantes en la distribución y estructura de comunidades microbianas, así como, para reconocer microtexturas biosedimentarias y patrones de biomineralización relacionada con el ambiente de aguas circundantes. Los aspectos biosedimentológicos caracterizados en BSI también tienen relevancia astrobiológica para la búsqueda de biosignaturas como una herramienta que permite analizar comunidades y comparar microscópicamente sedimentos fósiles y recientes derivados de una gran diversidad de ambientes sedimentarios. Debido a que son fácilmente reconocibles, aislables y sujetos a una gran variedad de técnicas y análisis, los tapetes microbianos de cianobacterias representan ya en sí mismos un gran cúmulo de biosignaturas relevantes en astrobiología (Chacon, 2010), al mismo tiempo que sirven también como análogos modernos de estromatolitos o de microbialitas porque reflejan una complejidad de factores y variaciones diurnas bien marcadas a lo largo de la verticalidad del tapete. Aunque probablemente los tapetes de cianobacterias no sean relictos o análogos modernos de los primeros estromatolitos, si constituyen microecosistemas que proporcionan modelos para identificar mecanismos de acreción de estas estructuras organosedimentarias; además su análisis provee sin duda otra vía para estudiar interacciones microbio-mineral dentro de una matriz orgánica tan compleja como el EPS. Estas características, además de vincularlos con los estromatolitos, hacen que los tapetes sean reservorios dinámicos de una gran cantidad de biosignaturas microbianas útiles en paleontología y astrobiología.

\section{Agradecimientos}

El presente proyecto ha sido apoyado gracias al financiamiento del proyecto de investigación financiado por PROMEP-103-5/08/2523 (SEP), por CONACyT-P2-83500CB y por el proyecto PAICyT-CT 1381-12 de la Universidad Autónoma de Nuevo León (UANL). Agradecemos de manera muy especial la amable invitación e iniciativa de los Editores, las atinadas sugerencias de los árbitros, y el profesional y paciente trabajo del equipo de revisión técnica del Boletín de la Sociedad Geológica Mexicana en cada paso del proceso.

\section{Referencias}

Allwood, A.C., Walter, M.R., Kamber, B.S., Marshall, C.P., Burch, I.W., 2006, Stromatolite reef from the Early Archaean era of Australia: Nature, 441, 714-718.

Anagnostidis, K., Komárek, J., 1988, Modern approach to the classification system of cyanophytes 3 - Oscillatoriales: Archiv für Hydrobiologie, 80 (Algological Studies 50-53), 327-472. 
Anderson, B.D., 1984, El manantial hidrotermal Baño de San Ignacio en Linares, N.L., México: Linares, N.L., Facultad de Ciencias de la Tierra, UANL, Reporte Técnico-FCT, 19 p.

Anderson, B.B., Aguilera, V.M., 1986, Push faults, a conceptual model for groundwater exploration in the Sierra Madre Oriental foreland: Zentralblatt für Geologie und Paläontologie 9-10, 1149-1160.

Arp, G., Reimer, A. and Reitner, J., 1999, Calcification in cyanobacterial biofilms of alkaline salt lakes: European Journal of Phycology, 34, 393-403.

Awramik, S.M., Margulis, L., 1977, Paleobiology of Stromatolites, en Ponnamperuma, C. (ed.), Chemical evolution of the Early Precambrian: New York, Academic Press, 111-131.

Awramik, S.M., Riding, R., 1988, Role Of Algal Eukaryotes In Subtidal Columnar Stromatolite Formation: Proceedings Of The National Academy Of Sciences Of The United States Of America, 85, 1327-1329.

Barbarín, J.M., Hubberten, H.W., Meiburg, P., Rodríguez de Barbarín, C.O., 1988, Hidrogeoquímica de las aguas termales del Baño San Ignacio, Linares, Nuevo León, México: Linares, N.L., Facultad de Ciencias de la Tierra, UANL, Actas de la FCT, UANL 3, 99 p.

Benítez González, M.C., 1997, Contribución a la caracterización ecológica y socio-económica de la región Baño San Ignacio, Linares, Nuevo León, México: Linares, N.L., Facultad de Ciencias Forestales, UANL, Tesis de Maestría, $137 \mathrm{p}$.

Black, M., 1933, The algal sediments of Andros Island, Bahamas: Royal Society of London Philosophical Transactions Serie B, 122, 165-192.

Blinn, D.W., Hevly, R.H., Davis, O.K., 1994, Continuous Holocene record of diatom stratigraphy, paleohydrology, and anthropogenic activity in a spring-mound in Southwestern United States: Quaternary Research, 42, 197-205.

Bonny, S., Jones, B., 2008, Experimental precipitation of barite $\left(\mathrm{BaSO}_{4}\right)$ among streamers of sulfur-oxidizing bacteria: Journal of Sedimentary Research, 78, 357-365.

Braissant, O., Cailleau, G., Dupraz, C., Verrecchia, A. P., 2003, Bacterially induced mineralization of calcium carbonate in terrestrial environments: the role of exopolysaccharides and amino acids: Journal of Sedimentary Research, 73, 485-490.

Burne, R.V., Moore, L.S., 1987, Microbialites: organosedimentary deposits of benthic microbial communities: Palaios, 2, 241-254.

Cantú, C., Guerra, R., González, F., Rocha, L., 2001, Programa de Manejo del área Natural Protegida Baño de San Ignacio, Nuevo León, México: Monterrey, Subsecretaría de Ecología, SEDUOP, Gobierno del Estado de Nuevo León, México, 125 p.

Chacon, E., 2010, Microbial Mats as a Source of Biosignatures, en Seckback, J., Oren, A. (eds.), Microbial Mats: Heidelberg, Springer, 151-181.

Chacon, E., Berrendero-Gomez, E., Montejano, G., Malda-Barrera, J., Sanchez-Ramos, M.A., 2011, Are Cyanobacterial Mats the precursors of stromatolites?, en Seckback, J., Tewari, V. (eds), Stromatolites: Interactions of Microbes with Sediments: Heidelberg, Springer 313-341.

Chafetz, H.S., Buczynski, C., 1992, Habit of bacterially induced precipitates of calcium carbonate and the influence of medium viscocity on mineralogy: Journal of Sedimentary Petrology, 61, 226-231.

Chávez-Cabello, G., Cossío-Torres, T., Peterson-Rodríguez, R., 2004, Change of the maximum principal stress during the Laramide Orogeny in the Monterrey Salient, northeast Mexico, en Sussman, A.J., Weil, A.B. (eds.), Orogenic curvature; integrating palomagnetic and structural analyses: Geological Society of America, Special Paper 383, 145-160.

Cohen, Y., Rosenberg, E., 1989, Microbial Mats: Physiological Ecology of Benthic Microbial Communities: Washington, D.C., American Society of Microbiology, $494 \mathrm{p}$.

Costerton, J.W., Lewandowski, Z., Caldwell, D.E., Korber, D.R., Lappin-Scott, H.M., 1995, Microbial biofilms: Annual Review of Microbiology, 49, 711-745.

De Cserna, Z., 1989, An outline of the geology of Mexico, en Bally, A.W., Palmer, A.R. (eds.), Decade of North American Geology, Volume A:
The Geology of North America - An overview, Boulder, Geological Society of America, 233-264.

Della Porta, G., 2015, Carbonate build-ups in lacustrine, hydrothermal and fluvial settings: comparing depositional geometry, fabric types and geochemical signature, en Bosence, D.W.J., Gibbons, K.A., Le Heron, D.P., Morgan, W.A., Pritchard, T., Vining, B.A. (eds), Microbial Carbonates in Space and Time: Geological Society of America, Special Publication, 418, 16-68.

Des Marais, D. J., 2003, Biogeochemistry of Hypersaline Microbial Mats: Biological Bulletin, 204, 160-167.

Dillon, J.G., Castenholz, R.W., 1999, Scytonemin, a cyanobacterial sheath pigment, protects against UVC radiation: Implications for early photosynthetic life: Journal of Phycology, 35, 673-681.

Dupraz, C., Visscher, P.T., 2005, Microbial lithification in marine stromatolites and hypersaline mats: Trends Microbiology, 13, 429-438.

Dupraz, C., Reid, R.P., Braissant, O., Decho, A.W., Norman, R.S., Visscher, P.T., 2009, Processes of carbonate precipitation in modern microbial mats: Earth Science Reviews, 96, 141-162.

Esteve, I., Martínez-Alonso, M., Mir, J., Guerrero, R., 1992, Distribution, Typology and Structure of Microbial Mat Communities in Spain: a preliminary study: Limnetica, 8, 185-195.

Fenchel, T., King, G.M., Blackburn, T.H., 1998, Bacterial Biogeochemistry: London, Academic Press, 307 p.

Garza-Castillo, A.M., 2006, Caracterización hidrogeoquímica de las aguas termales del Baño San Ignacio, Linares, Nuevo León, México: Linares, N.L., Facultad de Ciencias de la Tierra, UANL, Bs. Tesis, $96 \mathrm{p}$.

Geitler, L., 1932, Cyanophyceae. Rabenhorst's Kryptogamen Flora 14, Leipzig, Akademische Verlagsgesellschaft, 1196 p.

Gerdes, G., Claes, M., Dunajtschik-Piewak, K., Riege, H., Krumbein, W.E., Reineck, H.E., 1993, Contribution of microbial mats to sedimentary surface structures: Facies, 29, 61-74.

Gischler, E., Gibson, M.A., Oschmann, W., 2008, Giant Holocene Freshwater Microbialites, Laguna Bacalar, Quintana Roo, Mexico: Sedimentology, 55, 1293-1309.

Goldhammer, R.K., 1999, Mesozoic sequence stratigraphy and paleogeographic evolution, Northeast Mexico, en Bartolini, C., Wilson, J.L., Lawton, T.F. (eds.), Mesozoic Sedimentary and Tectonic History of North-Central Mexico, Geological Society of America, Special Paper 340, 1-58.

Golubic, S., 1983, Stromatolites, fossil and recent, a case history, en Westbroek, P., De Jong, E.W. (eds), Biomineralization and Biological Metal Accumulation: Dordrecht, D. Reidel Publishing Company, 313-326.

Golubic, S., Violante, C., Plenkovic, A., Grgasovic, T., 2008, Travertines and calcareous tufa deposits: an insight into diagenesis: Geologia Croatica, 61, 363-378.

Hem, J.D., 1985, Study and interpretation of the chemical characteristics of natural water: USA, U. S. Geological Survey, Water Supply Paper 2254.

Hoehler, T.M., Bebout, B.M., Des Marais, D.J., 2001, The role of microbial mats in the production of reduced gases on the early Earth: Nature, 412, 324-327.

Hoffmann, M., Rodríguez de Barbarín, C.O., Werner, J., 1992, Investigaciones geológicas e hidrogeológicas en el área del Baño San Ignacio, Linares, N.L., México: Linares, N.L., Facultad de Ciencias de la Tierra, UANL, Actas de la Facultad de Ciencias de la Tierra, UANL Linares 7, 171-176.

Jones, B., Renaut, R.W., 1996, Morphology and growth of aragonite crystals in hot-spring travertines at Lake Bogoria, Kenya Rift Valley: Sedimentology, 43, 323-340.

Komárek, J., Anagnostidis, K., 1999, Cyanoprokaryota Teil 1: Chroococcales, en Ettl, H., Gärtner, G., Heynig, G., Mollenhauer, D. (eds.), Süßwasserflora von Mitteleuropa: Band 19/1, Spektrum Akadamischer Verlag, Heidelberg, 548 p.

Komárek, J., Golubic, S., 2005, Proposal for unified nomenclatural rules for Cyanobacteria vs. Cyanophytes: "Cyano-Guide", en Hoffmann, L. (ed.), Nomenclature of Cyanophyta/Cyanobacteria: roundtable 
on the unification of the nomenclature under the Botanical and Bacteriological Codes: Archives of Hydrobiology/Algological Studies-(Cyanobacterial Res. 6), 117, 17-18.

López-Ramos, E., 1982, Geología de México. Tomo II: México, D. F., Consejo Nacional de Ciencia y Tecnología, $454 \mathrm{p}$.

Lowe, D.R., 1980, Stromatolites 3400-Myr old from the Archean of Western Australia: Nature, 284, 441-443.

Mudd, G.M., 2000, Mound springs of the Great Artesian Basin in South Australia: a case study from Olympic Dam: Environmental Geology, $39,463-476$.

Noffke, N., Eriksson, K.A., Hazen, R.M., Simpson, E.L., 2006, A new window into Early Archean life: Microbial mats in Earth's oldest siliciclastic tidal deposits (3.2 Ga Moodies Group, South Africa): Geology, 34(4), 253-256.

Noffke, N., Paterson, D., 2008, Microbial interactions with physical sediment dynamics, and their significance for the interpretation of Earth's biological history: Geobiology, 6, 1-4.

Pentecost, A., 1990, The formation of travertine shrubs: Mammoth Hot Springs, Wyoming: Geological Magazin, 127, 159-168.

Pentecost, A., 2003, Cyanobacteria associated with hot spring travertines: Canadian Journal of Earth Sciences, 40, 1447-1457.

Pentecost, A., 2005, Travertine. Berlin-Heidelberg-New York, Springer, $445 \mathrm{p}$.

Pentecost, A., Jones, B., Renaut, R.W., 2003, What is hot spring?: Canadian Journal of Earth Sciences, 40,1443-1146.

Periódico Oficial del Gobierno de Nuevo León (POENL), 2000, Tomo CXXXVII, Monterrey, N.L., viernes 24 de noviembre de 2000 . No. 141. p. 94.

Reid, R.P., Visscher, P.T., Decho, A.W., Stolz, J.F., Bebout, B.M., Dupraz, C.P., Macintyre, I.G., Paerl, H.W., Pinckney, J.L., Prufert-Bebout, L., Steppe, T.F., DesMarais, D.J., 2000, The role of microbes in accretion, lamination and early lithification of modern marine stromatolites: Nature, 406, 989-992.

Rodríguez de Barbarín, C.O., Barbarín, J.M., 1993, Influencia de la geología regional, los ciclos estacionales y los asentamientos humanos en la caracterización de las aguas superficiales de la cuenca de Linares-Cerro Prieto, N.L., México: Geofísica Internacional 32, 221-235.

Ruiz, M.A., 1990, Zur Gliederung, Verbreitung und oekologischen Bewertung der Boeden in der Region von Linares, N.L., Mexiko: Gottinger Beitraeger zur Land- und Forstwirstschaft in den Tropen und Subtropen, 56, 81-96.

Ruiz-Martinez, M.A., Werner J., 1997, Research into the Quaternary sediments and climatic variations in NE Mexico: Quaternary International, 43/44, 145-151.

Schidlowski, M., Aharon, P., 1992, Carbon cycle and carbon isotope record: Geochemical impact of life over 3.5 Ga of Earth history, en Schidlowski, M., Golubic, S., Kimberley, M.M., McKirdy, D.M., Trudinger, P.A. (eds), Early Organic Evolution: Implications for Mineral and Energy Resources: Berlin, Springer, 147-175.

Schneider, D., Arp, G., Reimer, A., Reitner, J., Daniel, R., 2013 , Phylogenetic Analysis of a Microbialite-Forming Microbial Mat from a Hypersaline Lake of the Kiritimati Atoll, Central Pacific: Public Library of Science PLoS ONE, 8(6), 1-14.

Secretaría de Programación y Presupuesto, 1993, Carta Hidrológica de Aguas Superficiales G14-11, escala: 1:250,000.

SEDUOP/FCF-UANL, 2000, Programa de manejo del área natural protegida Baño San Ignacio. Gobierno del Estado de Nuevo León, Monterrey, N.L. 76 p.

Seibertz, E., 1998, Evolution of the Mid-Cretaceous in Northern Mexico under paleoceanographic aspects: Revista Mexicana de Ciencias Geológicas, 15, 87-90

Secretaría de Ecosistemas Medio Ambiente Recursos Naturales (SEMARNAT), 2010, Estrategia Mexicana de Comunicación,
Educación, Concienciación y Participación (CECOP) en Humedales 2010-2015, Primera Edición: SEMARNAT, México. 37 p.

Sohl, N.F, Martínez, R.E., Salmerón-Ureña, P., Soto-Jaramillo, F., 1991, Upper Cretaceous, en Salvador, A. (ed.), The Gulf of Mexico Basin: Boulder, Colorado, Geological Society of America, The Geology of North America, Volume J, 205-215.

Spadafora, A., Perri, E., McKenzie, J.A., Vasconcelos, C., 2010, Microbial biomineralization processes forming modern $\mathrm{Ca}: \mathrm{Mg}$-carbonate stromatolite, Sedimentology, 57, 27-40

Stal, L.J., Caumette, P., 1994, Microbial Mats; Structure, Development and Environmental Significance. NATO ASI Series: Springer-Verlag, Berlin. 463 p.

Stal, L.J., 1995, Physiological ecology of cyanobacteria in microbial mats and other communities: New Phytologist, 131, 1-32.

Stolz, J.F., 2000, Structures of microbial mats and biofilms, en Riding, R.E., Awramik, S.M. (eds.), Microbial Sediments: Springer-Verlag, Berlin, 1-8.

Stoodley, P., Sauer, K., Davies, D.G., Costerton, J.W., 2002, Biofilms as complex differentiated communities: Annual Reviews in Microbiology, 56, 187-209.

Toth, J., 1999, Groundwater as a geologic agent: An overview of the causes, processes, and manifestations: Hydrogeology Journal, 7, 1-14.

Treviño-Cázares, A., Ramírez-Fernández, J.A., Velasco-Tapia, F., Rodríguez-Saavedra, P., 2005, Mantle-xenoliths and their host magmas in the Eastern Alkaline Province: International Geology Review, 47, 1270-1286.

van der Meer, M.T. J., Schouten, S., Bateson, M.M., Nubel, U., Wieland, A., Kuhl, M., de Leeuw, J. W., Sinninghe Damste, J.S., Ward, D.M., 2005, Diel Variations in Carbon Metabolism by Green NonsulfurLike Bacteria in Alkaline Siliceous Hot Spring Microbial Mats from Yellowstone National Park: Applied Environmental Microbiology, 71, 3978-3986.

Van Gemerden, H., 1993, Microbial mats: a joint venture: Marine Geology, $113,3-25$.

Visscher, P.T., Stolz, J. F., 2005, Microbial mats as bioreactors, populations, processes, and products: Palaeogeography, Palaeoclimatology and Palaeoecology, 219, 87-100.

Visscher, P.T., Reid, R.P., Bebout, B.M., 2000, Microscale observations of sulfate reduction: correlation of microbial activity with lithified micritic laminae in modern marine stromatolites: Geology, 28, 919-922.

Westall, F., De Ronde, C.E.J., Southam, G., Grassineau, N., Colas, M., Cockell, C., Lammer, H., 2006, Implications of a 3.472-3.333 Gaold subaerial microbial mat from the Barberton greenstone belt, South Africa for the UV environmental conditions on the early Earth: Philosophycal Transactions of the Royal Society of London, $361,1857-1875$.

Winsborough, B.M., 2000, Diatoms and benthic microbial carbonates, en Riding, R.E., Awramik, S.M. (eds.), Microbial Sediments: SpringerVerlag, Berlin, 76-83.

Winsborough, B. M., Golubic, S., 1987, The role of diatoms in stromatolite growth: two examples from modern freshwater settings: Journal of Phycology, 23, 195-201

Winsborough, B.M., Seeler, J-S, Golubić, S., Folk, R.L., Maquire, B., 1994, Recent fresh-water lacustrine stromatolites, stromatolitic mats and oncoids from Northeastern Mexico, en Bertand-Sarfati, J., Monty, C. (eds.), Phanerozoic Stromatolites II. Kluwer Academic Publishers, Amsterdam, 71-100.

Manuscrito recibido: Junio 16, 2014

Manuscrito corregido recibido: Enero 6, 2015

Manuscrito aceptado: Febrero 13, 2015 